\title{
Implementation and management of private traffic limitation in urban areas: experiences and methodologies
}

\author{
M. E. Lopez Lambas ${ }^{1} \&$ S. Ricci ${ }^{2}$ \\ ${ }^{1}$ Universidad Politecnica de Madrid, Spain \\ ${ }^{2}$ Sapienza Università di Roma, DICEA, Area Trasporti, Italy
}

\begin{abstract}
This paper shows the results of a research aimed to formulate a general model for supporting the implementation and management of an urban road pricing scheme. After a preliminary work, to define the state of the art in the field of sustainable urban mobility strategies, the problem has been theoretically set up in terms of transport economy, introducing the external costs' concept duly translated into the principle of pricing for the use of public infrastructures. The research is based on the definition of a set of direct and indirect indicators to qualify the urban areas by land use, mobility, environmental and economic conditions. These indicators have been calculated for a selected set of typical urban areas in Europe on the basis of the results of a survey carried out by means of a specific questionnaire. Once identified the most typical and interesting applications of the road pricing concept in cities such as London (Congestion Charging), Milan (Ecopass), Stockholm (Congestion Tax) and Rome (ZTL), a large benchmarking exercise and the cross analysis of direct and indirect indicators, has allowed to define a simple general model, guidelines and key requirements for the implementation of a pricing scheme based traffic restriction in a generic urban area. The model has been finally applied to the design of a road pricing scheme for a particular area in Madrid, and to the quantification of the expected results of its implementation from a land use, mobility, environmental and economic perspective.
\end{abstract}

Keywords: urban mobility management, traffic limitation, road pricing. 


\section{Introduction}

Mobility is a key issue for the management of urban areas due to its consequences both on land use and environment. Almost $80 \%$ of the population of the European Union now live in towns and the mobility served by private car is very high and increasing at the rate of 3 million vehicles a year, with the associated phenomena of traffic congestion. The damaging consequences of congestion are visible on economy, environment, public health and quality of life in other words, the pillars of the sustainable development. Actions against this situation require to shift the current modal split in favour of alternatives other than private car. The mobility policies based on the translation into internal costs of a part of the external costs caused by the use of the private car, move in this direction. Within this general framework, a pricing based strategy is a promising solution to control and restrict road traffic progressively developed in European urban areas and worldwide.

\section{Principles and evaluation of urban road pricing}

An in depth analysis of measures acting on the sustainability of urban mobility cannot be developed without a process of monitoring and an ex-post evaluation of its effectiveness (Gervasoni and Sartori [1]). Specifically, in order to quantify the effects of traffic management measures on urban networks, a baseline and some direct and indirect indicators may be identified, considered both for the benchmarking of congestion pricing experiences and for the production of a general model of urban road pricing. To this purpose, four classes of indicators have been identified: urbanism (U), transportation $(\mathrm{T})$, economy (E) and environment (A), with their direct respective indicators indicated in Tables 1 to 4 .

The indirect inter-class indicators have been derived on these bases and are listed in Table 5.

Table 1: $\quad$ Identified urbanism (U) indicators and corresponding units.

\begin{tabular}{|c|c|}
\hline Indicators & Units \\
\hline U1 - Total area of town & {$\left[\mathrm{km}^{2}\right]$} \\
\hline U2 - Road pricing area & {$\left[\mathrm{km}^{2}\right]$} \\
\hline U3 - Road pricing area perimeter & {$[\mathrm{km}]$} \\
\hline $\begin{array}{l}\text { U4 - Road pricing area incidence on total area of } \\
\text { town }\end{array}$ & [\%] \\
\hline U5 - Town population & [resident inhabitants] \\
\hline U6-Road pricing area population & [resident inhabitants] \\
\hline U7 - Road pricing area density & [resident inhabitants $\left./ \mathrm{km}^{2}\right]$ \\
\hline U8 - Road pricing area employed population & [working inhabitants] \\
\hline U9 - Road pricing area tertiary activities density & [commercial and service activities $/ \mathrm{km}^{2}$ ] \\
\hline U10 - Road pricing area accessibility & [gates number] \\
\hline U11 - Road pricing area accessibility density & [gates number $/ \mathrm{km}$ ] \\
\hline
\end{tabular}


Table 2: $\quad$ Identified transportation $(\mathrm{T})$ indicators and corresponding units.

\begin{tabular}{|l|c|}
\multicolumn{1}{c}{ Indicators } & Units \\
\hline$T 1-$ Mean road pricing area entering traffic & [vehicle/day] \\
\hline$T 2-$ Mean road pricing area entering traffic reduction & {$[\%]$} \\
\hline$T 3-$ Mean road pricing area running & {$[$ vehicle $x \mathrm{~km}]$} \\
\hline$T 4-$ Mean road pricing area running reduction & {$[\%]$} \\
\hline$T 5-$ Mean road pricing area private traffic commercial speed & {$[\mathrm{km} / \mathrm{h}]$} \\
\hline$T 6-$ Mean road pricing area private traffic commercial speed increase & {$[\%]$} \\
$T 7-$ Mean road pricing area public transport commercial speed & {$[\mathrm{km} / \mathrm{h}]$} \\
\hline$T 8-$ Mean road pricing area public transport commercial speed increase & {$[\%]$} \\
\hline
\end{tabular}

Table 3: $\quad$ Identified economic (E) indicators and corresponding units.

\begin{tabular}{|c|c|}
\hline Indicators & Units \\
\hline E1-Initial investment costs & {$[\epsilon]$} \\
\hline E2-Revenue & [€/year] \\
\hline E3-Management costs & [€/year] \\
\hline E4-Profit & [€/year] \\
\hline
\end{tabular}

Table 4: $\quad$ Identified environmental (A) indicators and corresponding units.

\begin{tabular}{|l|c|}
\multicolumn{1}{c|}{ Indicators } & Units \\
\hline A1 - PM10 emissions without road pricing implementation & {$[g]$} \\
\hline A2 - PM10 emissions with road pricing implementation Revenue & {$[g]$} \\
\hline A3 - PM10 emissions reduction & {$[\%]$} \\
\hline A4 - NOx emissions without road pricing implementation & {$[g]$} \\
\hline A5 - NOx emissions with road pricing implementation Revenue & {$[g]$} \\
\hline A6-NOx emissions reduction & {$[\%]$} \\
\hline
\end{tabular}

Table 5: $\quad$ Indirect inter-class indicators and corresponding units.

\begin{tabular}{|c|c|}
\hline Indicators & Units \\
\hline TU1 - Entering traffic / Road pricing area $=T 1 / U 2$ & [vehicle/day $\left./ \mathrm{km}^{2}\right]$ \\
\hline $\begin{array}{l}\text { TU2 - Entering traffic / Road pricing area employed } \\
\text { population }=T 1 / U 7\end{array}$ & [vehicle/day/working inhabitant] \\
\hline EU1 - Management costs $/$ Road pricing area $=E 3 / U 2$ & {$\left[\epsilon / \mathrm{km}^{2}\right]$} \\
\hline ETI - Initial investment costs $/$ Entering traffic $=E 1 / T 1$ & {$[\epsilon /$ vehicle / day] } \\
\hline ET2 - Revenue $/$ Entering traffic $=E 2 / T 1$ & [€/vehicle / day] \\
\hline
\end{tabular}

Once the indicators have been identified, a questionnaire was developed and sent to a selected group of people responsible for European road pricing programmes. It included 13 questions and was made available in three languages (English, Italian and Spanish) and submitted to those responsible for the implementation of those programmes in the following cities: Vienna (Austria), Rome (Italy), Burgos, Madrid, San Sebastián and Vitoria (Spain). Additional information has been collected on the website with references to other well- 
known road pricing experiences, such as Milan and Rome (Nussio [2]), Stockholm (Carle and Ellemce [3] and Elliasson and Lundberg [4]) and London (Dix [5]).

\section{European road pricing and traffic limitation experiences}

The implementation of urban road pricing is an almost consolidated experience since the first pilot case in 1975 in Singapore. Nevertheless the limited number and geographic extension of experiences all over the world does not allow to draw universal conclusions. In such as this context the present research tries to depict, from a careful comparative analysis of the main European experiences on the topic, feedback for the implementation of similar road pricing experiences in different urban contexts. The implementation process of these measures aims normally to translate into external costs the externalities generated by the use of private cars and to use the related income for sustainability mobility initiatives. In this framework a systematic benchmarking analysis, based on the indicators previously defined (Section 2), has been carried out to investigate the different existing approaches. The results of the benchmarking are shown below, with specific references to 4 urban areas, selected on the basis of their relevance and the available data.

\subsection{Urban context}

The urban area normally affected by road pricing measures is the CBD, surrounded as much as possible by a natural border where the entry gates are located along. In most cases the priced area concentrates many activities and/or residences, so that density of jobs and population is rather high despite of the limited extension of the area. The most extended road pricing area is located in London (about $41 \mathrm{~km}^{2}$ ), the second one in Stockholm $(29,5 \mathrm{~km})$, whilst the smaller are the Italian areas (Milan $8,2 \mathrm{~km}^{2}$ and Rome roughly $5,7 \mathrm{~km}^{2}$ ). The number of entry gates does not in any case exceed 50 , with only the exception of London, where the total amount of check point is 230 due to the need to monitor the internal movements, also subjected to payment. The data about the tested urban areas are summarized in Table 6.

In general, the road pricing timing is concentrated on the periods where the congestion is higher: a maximum of 12 hours in the period between 6.30 (earliest start Rome) and 19.30 (latest closing Milan) in working days. Extension to the weekends exists in Rome for afternoon, evening and night periods.

\subsection{Effects on traffic}

In all the situations a certain reduction of entering traffic was experienced, though this clearly depends upon the fares and the traffic management strategies in the town: in Rome the reduction of the entering flows ranges from $15 \%$ to $20 \%$ (18\% mean value) (Lopez-Lambas [6]); in Stockholm the mean value is reached in Milan. A more general summary of measured effects on transportation indicators is reported in Table 7. 
Table 6: Urban area indicators for a set of relevant experiences.

\begin{tabular}{|c|c|c|c|c|}
\hline Indicators & London & Milan & Rome & Stockholm \\
\hline $\begin{array}{l}\text { T1 - Mean road pricing area entering traffic } \\
\text { [vehicle / day] }\end{array}$ & 221,000 & 73,000 & 70,000 & 286,000 \\
\hline $\begin{array}{l}T 2 \text { - Mean road pricing area entering traffic } \\
\text { reduction [\%] }\end{array}$ & 14 & 14 & 18 & 18 \\
\hline $\begin{array}{l}\text { T3 - Mean road pricing area running [vehicle } \\
x \mathrm{~km} \text { ] }\end{array}$ & $1,020,000$ & $N A$ & $N A$ & $N A$ \\
\hline $\begin{array}{l}\text { T4 - Mean road pricing area running } \\
\text { reduction }[\%]\end{array}$ & 10 & $N A$ & $N A$ & 14 \\
\hline $\begin{array}{l}\text { T5 - Mean road pricing area private traffic } \\
\text { commercial speed }[\mathrm{km} / \mathrm{h}]\end{array}$ & 17.0 & 18.0 & $N A$ & $N A$ \\
\hline $\begin{array}{l}\text { T6 - Mean road pricing area private traffic } \\
\text { commercial speed increase [\%] }\end{array}$ & $N A$ & $N A$ & 4 & $N A$ \\
\hline $\begin{array}{l}\text { T7 - Mean road pricing area public transport } \\
\text { commercial speed }[\mathrm{km} / \mathrm{h}]\end{array}$ & 10.6 & 9.4 & $N A$ & 18.0 \\
\hline $\begin{array}{l}\text { T8 - Mean road pricing area public transport } \\
\text { commercial speed increase [\%] }\end{array}$ & $N A$ & 7 & 10 & $N A$ \\
\hline
\end{tabular}

Table 7: $\quad$ Transportation indicators for a set of relevant experiences.

\begin{tabular}{|c|c|c|c|c|}
\hline Indicators & London & Milan & Rome & Stockholm \\
\hline U1 - Total area of the town $\left[\mathrm{km}^{2}\right]$ & 1579 & 184 & 1285 & 190 \\
\hline U2 - Road pricing area $\left[\mathrm{km}^{2}\right]$ & 41.00 & 8.20 & 5.70 & 29.50 \\
\hline $\begin{array}{l}\text { U6 - Road pricing area population } \\
\text { [inhabitants] }\end{array}$ & 432,000 & 77,000 & 53,000 & 275,000 \\
\hline $\begin{array}{l}\text { U7 - Road pricing area density } \\
\text { [inhabitants } / \mathrm{km}^{2} \text { ] }\end{array}$ & 10,537 & 9,390 & 9,298 & 9,322 \\
\hline $\begin{array}{l}\text { U8 - Road pricing area employed population } \\
\text { [working inhabitants] }\end{array}$ & & & & \\
\hline $\begin{array}{l}\text { U9 - road pricing area tertiary activities } \\
\text { density [commercial and service activities / } \\
\left.\mathrm{km}^{2}\right]\end{array}$ & 31,098 & $N A$ & 22,105 & $N A$ \\
\hline
\end{tabular}

The effects on the global traffic congestion exist, but its evaluation is only indirectly measured by variations on the commercial speed, indicator only directly available in Rome (-4\%), while in London is experienced a $26 \%$ reduction of mean running times, in Milan a reduction of $4,7 \%$ of mean flows/capacity ratio, and in Stockholm a 50\% reduction of the mean queue lengths.

\subsection{Economic results}

In economic terms the results of all assessed urban road pricing schemes are very positive in general terms. This means that the systems are normally capable to achieve congestion reduction goals within a sustainable financial framework. The use and destination of the revenues is not always made available to the public. However there are different situations: in London the "Congestion Charging" finances the transportation planning activities, while in Milan the 
revenues coming from the "Ecopass" are earmarked to sustainable mobility measures, (mainly public transport improvement).

The values of the economic indicators are synthetically reported in Table 8 .

Table 8: $\quad$ Economic indicators for a set of relevant experiences.

\begin{tabular}{|l|c|c|c|c|}
\multicolumn{1}{|c|}{ Indicators } & London & Milan & Rome & Stockholm \\
\hline E1 - Initial investment costs [ME] & 179,38 & 6,20 & 7,30 & 190,00 \\
\hline E2 - Revenue [ME / year] & 296,76 & 12,06 & 58,00 & 85,00 \\
\hline E3 - Management costs [ME/ & 145,06 & 6,50 & 3,20 & 39,30 \\
year] & 151,70 & 5,56 & 54,80 & 45,70 \\
\hline E4 - Profit [ME / year] & & & & \\
\hline
\end{tabular}

\subsection{Effects on the environment}

The only urban road pricing scheme specifically targeted to reduce the emissions is the so called "Ecopass" in Milan. Certainly many others are reaching environmental goals without specifically aiming to this purpose (i.e. those where fees are not linked to the environmental performance of the vehicles), or do not reach this kind of goals due to negative secondary effects (Lopez-Lambas [6]) (i.e. a strong increase of motorcycles traffic in Rome). Moreover, in many cases it is difficult to quantify the specific impacts of road pricing in conjunction with the effects of other mobility management measures (Monzon and LopezLambas [7]).

The values of the environmental indicators measured for the experiences of the test set are reported in Table 9.

Table 9: Environmental indicators for a set of relevant experiences.

\begin{tabular}{|l|c|c|c|c|}
\hline \multicolumn{1}{|c|}{ Indicators } & London & Milan & Rome & Stockholm \\
\hline $\begin{array}{l}\text { A1 - PM10 emissions without } \\
\text { road pricing implementation [g } \\
\text { day] }\end{array}$ & $N A$ & $N A$ & $N A$ & 64,77 \\
\hline $\begin{array}{l}\text { A2 - PM10 emissions with road } \\
\text { pricing implementation [g / day] }\end{array}$ & $N A$ & $N A$ & 11,00 & 63,01 \\
\hline $\begin{array}{l}\text { A3 - PM10 emissions reduction } \\
{[\%]}\end{array}$ & 4,85 & 6,00 & $N A$ & 2,70 \\
\hline $\begin{array}{l}\text { A4 - NOx emissions without road } \\
\text { pricing implementation [g / day] }\end{array}$ & $N A$ & $N A$ & $N A$ & 133,28 \\
$\begin{array}{l}\text { A5 - NOx emissions with road } \\
\text { pricing implementation [g / day] }\end{array}$ & $N A$ & $N A$ & 326,67 & 128,77 \\
\hline A6- NOx emissions reduction [\%] & 2,77 & 2,00 & $N A$ & 3,40
\end{tabular}

\section{From benchmarking to a general evaluation methodology}

Starting from the benchmarking indicators, the research was developed to identify consolidated relationships between indicators, useful to foresee and evaluate potential new applications for urban road pricing schemes. The analysis is limited to 14 indicators available for at least $75 \%$ of the reported urban experiences. The relevance of the correlations has been checked with the 
minimum square method based on a linear trend with equation $y=m x+b$ and the regression coefficient $\mathrm{R}^{2}$ representing the accuracy of the correlation, which resulted higher than 0.25 for $58 / 84=69 \%$ couples of indicators and higher than 0.50 for $45 / 84=54 \%$ couples. These data confirm the robustness of the correlation structure for the selected set of indicators.

On the basis of the most reliable trends, starting from the general objectives and the urban context peculiarities summarized by $U$ indicators, it is possible to calculate the correlated indicators expressing the potential of the proposed measure in terms of traffic ( $\mathrm{T}$ indicators), economy ( $\mathrm{E}$ indicators) and environment (A indicators). Moreover, it is possible to derive correlation inside the same group of indicators to cover the lack of data or their inconsistency.

Some examples of the indicators, which may be calculated by linear equations with high accuracy by means of this method, confirm its high potential:

- directly from typical urban context indicators:

$T 1$ (entering traffic) $=5498.1$ U2 +46423 [vehicle / day]

with $\mathrm{R}^{2}=0,74$

$E 2($ revenue $)=0.2008 U 7+1821.9[€ /$ year $]$

with $\mathrm{R}^{2}=0.91$

E3 $($ management costs $)=0.1065 U 7+977,93[€ /$ year $]$

with $\mathrm{R}^{2}=0.93$

- indirectly from traffic indicators:

$$
\begin{gathered}
A 3 \text { (reduction of PM10 emissions) }=0.00001 T 1+7.2502[\%] \\
\text { with } \mathrm{R}^{2}=0.85 \\
\text { A6 (reduction of NOx emissions) }=0.00006 T 1+1.5002[\%] \\
\text { with } \mathrm{R}^{2}=0.97
\end{gathered}
$$

- indirectly from economic indicators:

$$
\begin{gathered}
T 1(\text { entering traffic })=1032.6 E 1+63594 \text { [vehicle / day] } \\
\text { with } \mathrm{R}^{2}=0.96
\end{gathered}
$$

\section{The Madrid context}

Madrid is the capital city and the most populated town of Spain, as well as the $4^{\text {th }}$ most populated EU urban area, after Paris, London and Berlin. Madrid municipality today counts a population of about 3.1 million inhabitants and about 5.4 million for the whole metropolitan area. Both the density and the working districts distribution are irregular, but the central area plays a relevant role for both these aspects. The recent trend of population migrating towards the suburban areas brought a diversification in the transport behaviour too, with public transport playing a major role in the CBD (about $38 \%$ of modal split) and a large majority of private cars in the suburban areas (about $44 \%$ of modal split) (Monzon and Lopez-Lambas [7]). To fight against this increasing unsustainable mobility trend based on the excessive use of the private car, the municipality has implemented a set of measures: pedestrian areas, a parking regulation scheme 
(SER), public transport improvements, the upgrading of the M-30 ring road and the setup of the so-called Priority Residential Areas (APR, Área de Prioridad Residencial) in the central districts (Monzon et al. [8]).

Particularly the APR may be assimilated to the limited traffic zone (ZTL) in Rome, with the free right to enter for residents but without the need and the possibility to pay a fee to enter the area for not residents. In fact the main objective of the APR scheme is to reduce traffic flows, noise and pollution, as well as to regulate goods distribution. The 3 APR established in the period 20052006 (Letras, Cortes and Embajadores, Figure 1) cover about $2 \mathrm{~km}^{2}$, with about 67.000 inhabitants, with a total of 25 entry gates equipped with infrared cameras along the borders.
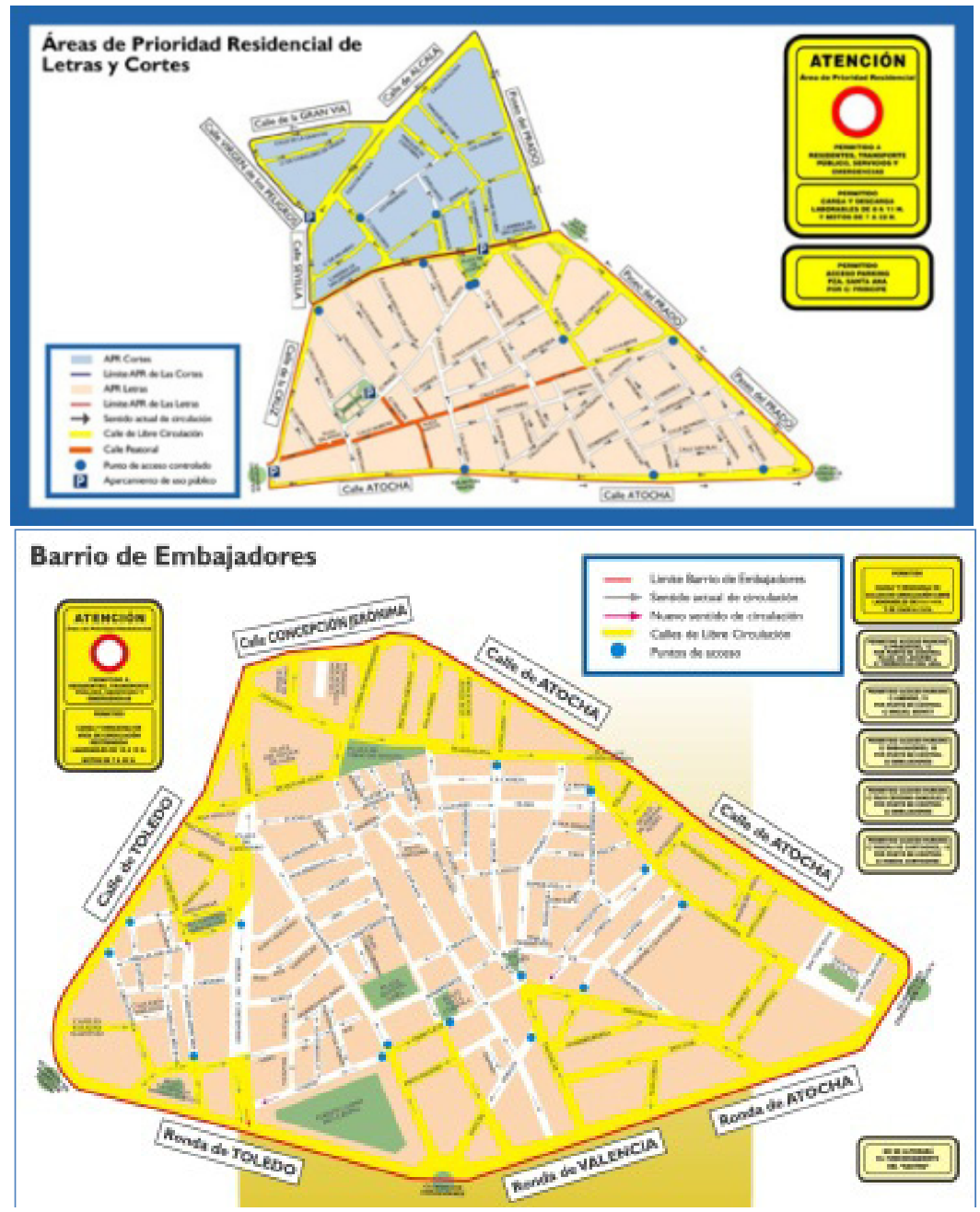

Figure 1: $\quad$ APR active in Madrid. 
The evaluation of the effects brought by the APR system is very complex due to the lack of a systematic monitoring process and to the simultaneous implementation of other measures. It was anyway verified the need to increase the efficiency of this system by the possibility of implementing a charging for access to the concerned areas hence, transforming the existing system into a typical road pricing scheme.

The methodology developed in this paper, synthetically described in Section 4, allows us to evaluate the potentially achievable results within this new scheme.

The typical starting indicators for the Madrid context are summarised in Table 10.

Table 10: Urban area indicators for Madrid.

\begin{tabular}{l|c} 
U1 - Total area of the town $\left[\mathrm{km}^{2}\right]$ & 606 \\
\hline U2 - Road pricing area $\left[\mathrm{km}^{2}\right]$ & 1.91 \\
\hline U5 - Town population [resident inhabitants] & $3,255,944$ \\
\hline U6 - Road pricing area population [inhabitants] & 67,000 \\
\hline U7 - Road pricing area density [inhabitants $\left./ \mathrm{km}^{2}\right]$ & 35,000 \\
\hline U10-Road pricing area accessibility [gates number] & 25
\end{tabular}

\section{Madrid case study implementation}

Starting from the typical indicators of the Madrid urban context, the original stochastic model previously explained allows to calculate the forecasted values of various indicators achievable in the transportation field by the translation of the APR system into a road pricing system, as summarised in Table 11.

Table 11: $\quad$ Transport indicators calculated for Madrid.

\begin{tabular}{l|c}
$T 1-$ Mean road pricing area entering traffic [vehicle / day] & 56,948 \\
\hline$T 2-$ Mean road pricing area entering traffic reduction [\%] & 17 \\
\hline$T 7-$ Mean road pricing area public transport commercial speed $[\mathrm{km} / \mathrm{h}]$ & 15.8
\end{tabular}

The same model allows us to forecast the investment costs for the APR transformation, including the preparatory studies required, communication and information campaigns towards citizens, air quality measurement equipment and implementation of a dedicated accounting system. Moreover, from the same data and the invariable management cost it is possible to estimate the yearly revenues of the road pricing scheme and to calculate the forecasted yearly profit (Table 12).

Table 12: $\quad$ Economic indicators calculated for Madrid.

\begin{tabular}{|l|c|}
\hline E1 - Initial investment costs [M€] & 20.79 \\
\hline E2-Revenue [M€ / year] & 24.47 \\
\hline E3-Management costs [M€ / year] & 1.20 \\
\hline E4 - Profit [M€ / year] & 23.27
\end{tabular}


Finally, the model allows us to estimate the reduction of emissions in the transformed APR area (Table 13).

Table 13: Environmental indicators calculated for Madrid.

A3 - PM10 emissions reduction [\%]

A6 - Nox emissions reduction [\%]

\section{Final remarks}

On the basis of the wide investigation carried out and the deep theoretical interpretation it has been formulated a general model capable to forecast key indicators for planning and management of an urban road pricing scheme. Though the availability of data for feeding the model has been experienced as a critical aspect, the high reliability of the model itself was confirmed by stochastic analysis. The model deals with direct and indirect indicators regarding land use, mobility, economy and environment, and it has been calibrated and validated on a test set of road pricing applications in European urban areas, confirming a wide potential.

The model application to the case study of Madrid, where a restricted traffic zone is planned to be transformed in a full urban road pricing scheme, has provided very interesting and complete results, including significant benefits for traffic congestion and environment, as well as relevant economic performances which will benefit the city competitiveness

\section{References}

[1] Gervasoni A., Sartori M. - Il road pricing: esperienze internazionali, costi, benefici e sostenibilità finanziaria - January 2007.

[2] Nussio F. - Rome, The mobility problems: Parking and Access Control Policies - Meeting in Barcelona Politechnic - Barcelona, November 2004.

[3] Carle M., Ellemce, H.B. - Congestion Charges in Stockholm - to be or not to be - COST 355 Working Group $2^{\text {nd }}$ meeting - Prague, October 2006.

[4] Elliasson J., Lundberg M. - Road Pricing in Urban Areas. Swedish Road Administration Borlanger - 2003.

[5] Dix M. - The Central London Congestion Charging Scheme. From Conception to Implementation - May 2002.

[6] Lopez-Lambas M.E. - Vacaciones en Roma: ZTL, ecopass y otras formas de entender el control de acceso al centro urbano - 2010 .

[7] Monzon A, Lopez-Lambas, ME: Impact assessment of a new parking pricing scheme in Madrid city centre, in proceedings of the 4th International Symposium on Travel Demand Management, Vienna-Semmering, July 2008.

[8] Monzon A., Vega L.A., Pardeiro A. - Reducing car trip and pollutant emission through strategic transport planning in Madrid, in Highway and Urban Environment - Springer - 2007. 